\title{
Nucleotide sequence of dihydrofolate reductase type VI
}

\author{
B. A. WYLIE* and H. J. KOORNHOF
}

Emergent Pathogen Unit of the Medical Research Council, University of the Witwatersrand and the South African Institute for Medical Research, Johannesburg 2000, South Africa

\begin{abstract}
Summary. The complete sequence of the type VI dihydrofolate reductase (DHFR) gene from plasmid pUK672 was determined. The structural gene coded for a polypeptide of 157 amino acids which had a deduced mol. wt of 17424 . Comparison with amino-acid sequences of the type I, type V and Escherichia coli $\mathrm{K} 12$ chromosomal DHFRs showed that there was $63 \%$, $61 \%$ and $31 \%$ homology respectively. Putative RNA polymerase and ribosomal binding sites were identified proximal to the initiation codon and a feature consistent with transcription termination was present distal to the coding region. Sodium dodecyl sulphate-polyacrylamide gel electrophoresis showed that the enzyme had a subunit mol. wt of 17500 .
\end{abstract}

\section{Introduction}

High-level resistance to trimethoprim (Tp) $(\mathrm{MIC}>$ $1000 \mathrm{mg} / \mathrm{L}$ ) is mediated by dihydrofolate reductases (DHFRs) which are resistant to the drug. The genes encoding these enzymes have been demonstrated in plasmids and transposons by which means they have also been found integrated into the bacterial chromosome. ${ }^{1}$ Several such enzymes have been described in gram-negative bacteria and classified according to their biochemical properties. These are the types I(a and $\mathrm{b}), \mathrm{II}(\mathrm{a}, \mathrm{b}$ and $\mathrm{c}), \mathrm{V}, \mathrm{VI}$ and VII. ${ }^{2}$

The nucleotide sequences of the types I, II and V DHFRs have been determined, ${ }^{3-5}$ and this has revealed considerable homology between enzymes of the same group, e.g., $>78 \%$ between type IIa, b and c. ${ }^{6,7}$ There is no sequence homology between the type I and type II, and the type II and type V genes. ${ }^{3,5}$ The type $V$ and type I DHFR genes have several similar features. Both genes code for a polypeptide of 157 amino acids and there is $75 \%$ amino-acid homology. ${ }^{5}$ However, these genes do not hybridise with one another. ${ }^{8}$ The type I and type V DHFR genes have regions which are homologous with the chromosomal DHFR gene of Escherichia coli $\mathrm{K} 12 .^{5}$

The type VI DHFR was originally found in Proteus mirabilis $\mathrm{J} 120$ isolated in South Africa. ${ }^{9}$ It has unique biochemical properties and, so far, has been found only in that country. The mol. wt, as determined by Sephadex column chromatography, was 10000 . This suggested that it might be a functional subunit of the type II DHFRs (mol. wt 9500), but hybridisation experiments with a type II probe failed to substantiate this. ${ }^{10}$

Received 6 Nov. 1990; revised version accepted 15 Jan. 1991. * Correspondence should be sent to: Dr B. A. Wylie, Department of Medical Microbiology, Medical School, York Road, Parktown, 2193 Johannesburg, South Africa.
This paper describes the sequence of the type VI DHFR gene and its relationship to other DHFRs.

\section{Materials and methods}

\section{Bacterial strains}

The gene encoding the type VI DHFR was isolated from P. mirabilis strain J120 (pUK672). The cloning vectors used were pUC18 and bacteriophages M13 mp18 and $\mathrm{mp} 19$, which were propagated in E.coli K12 strains JM103 and JM101 respectively. ${ }^{11}$

\section{DNA isolation and purification}

Plasmid DNA was purified by use of a Circleprep Kit (Bio 101 Inc., La Jolla, CA, USA) according to the manufacturer's instructions. DNA fragments were purified by separation in, and extraction from, lowmelting-point agarose as previously described. ${ }^{10}$

\section{Cloning procedure}

All cloning procedures with the vectors pUC18 and bacteriophages $\mathrm{M} 13 \mathrm{mp} 18$ and $\mathrm{mp} 19$ were performed according to the methods recommended by the supplier (Boehringer Mannheim). Purified plasmid DNA (pUK672) was partially or fully digested with EcoRI and ligated into suitably restricted plasmid pUC18 with T4 DNA ligase. The hybrid plasmids were transformed into competent $E$. coli K12 JM103 and clones containing the DHFR gene were selected on a medium containing trimethoprim lactate (Wellcome) $100 \mathrm{mg} / \mathrm{L}$, ampicillin $100 \mathrm{mg} / \mathrm{L}$, isopropyl- $\beta$-Dgalactoside and 5-bromo-4-chloro-3-indolyl- $\beta$-D-galactopyranoside (X-gal). Plasmid DNA from each clone was screened by the method of Maniatis et al. ${ }^{12}$ Similarly, DNA fragments from plasmid pUK672 
were ligated with suitably digested replicative form bacteriophage DNA and transformed into $E$. coli K12 JM101.

\section{Sequence determination}

Sequencing was performed by the chain termination method of Sanger et al. ${ }^{13}$ with an M13 sequencing kit (Boehringer) according to the manufacturer's instructions. The sequence was determined from both strands with the exception of $c .200 \mathrm{bp}$ at the $5^{\prime}$ end, the sequence of which was determined from one strand only. The sequence around the HindIII restriction site was confirmed with a 20-bp oligonucleotide primer which was complementary to the negative strand of the insert from position 266-285. The sequence was analysed with the Mount sequence analysis package (Genetics Software Centre, Department of Molecular and Cellular Biology, Biosciences West, University of Arizona, Tuscon, AZ 85721, USA).

\section{Results and discussion}

\section{Isolation of the type VI DHFR gene}

After partial digestion with EcoRI, the plasmid pUK672 was ligated with suitably restricted pUC18 and the hybrid plasmid was transformed into $E$. coli K12 JM103. A clone expressing trimethoprim resistance was found to contain a vector plasmid with an insert of $c .9 \cdot 0 \mathrm{~kb}$. The insert DNA was excised from the vector, purified and digested a second time with EcoRI. The fragments were recloned into pUC18. Clones expressing trimethoprim resistance were screened and the vector with the smallest insert (c. $1.5 \mathrm{~kb}$ ) was identified. Attempts to remove the c. $1 \cdot 5-\mathrm{kb}$ fragment from the plasmid revealed that the internal EcoRI site and the adjacent $X b a I$ site of the vector had been damaged. However, the PstI site was functional and was used together with the second EcoRI site to remove the insert.

Digestion of the $c .1 \cdot 5-\mathrm{kb}$ insert with a number of restriction enzymes showed that single sites for both $X b a I$ and $H$ indIII were present and that the fragments generated by each enzyme were large enough to contain the DHFR gene. These fragments were cloned into pUC18, but only the PstI/XbaI insert expressed trimethoprim resistance. This insert, which was c. $1.0 \mathrm{~kb}$ in size, also contained the HindIII site. The biochemical properties of the enzyme expressed by this gene were identical to those expressed by the gene in $P$. mirabilis $\mathrm{J} 120$.

For sequencing, three fragments were cloned into bacteriophages M13 mp18 and mp19. These were the c. 1.0-kb Pst I/XbaI fragment, the c. 600-bp PstI/ $H$ indIII fragment and the c. 400-bp HindIII/XbaI fragment (fig. 1).

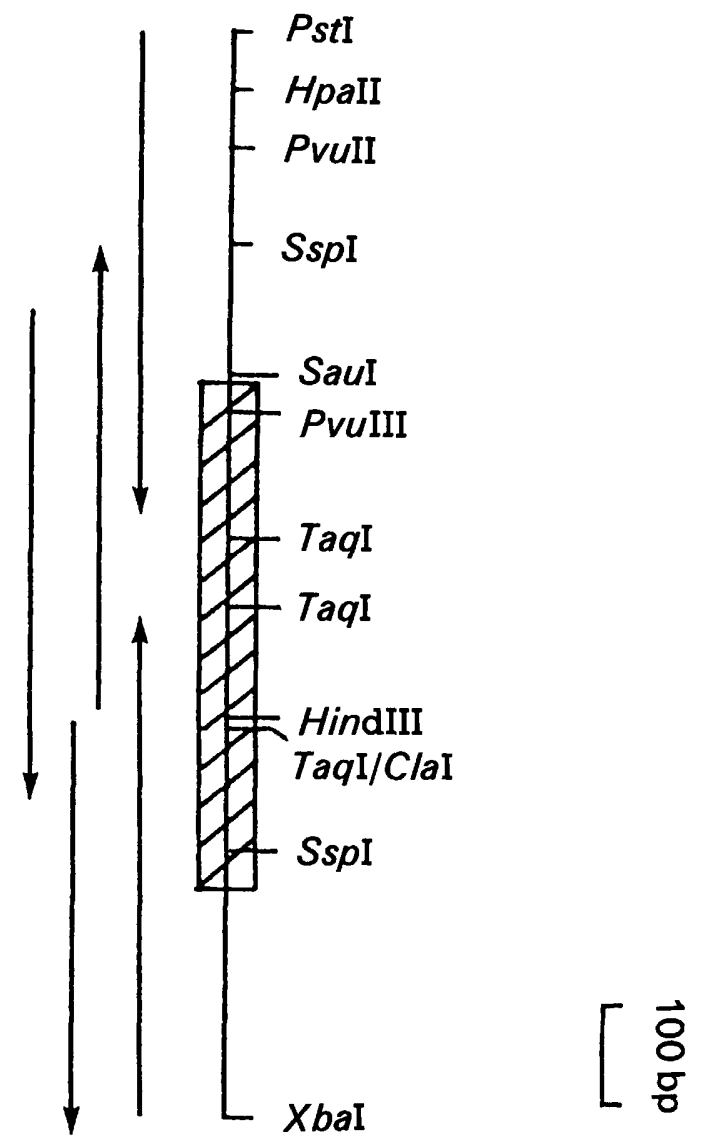

Fig. 1. Restriction map of the 1026-bp insert containing the type VI DHFR gene (cross-hatched area). Arrows indicate the direction and extent of sequencing.

\section{Nucleotide sequence of the type VI DHFR gene}

Because the type VI enzyme had been previously assigned a mol. wt of 10000 , a gene of about 240 $300 \mathrm{bp}$ was expected. Analysis of the sequence of the 1026 -bp insert yielded only one open reading frame (ORF) larger than 240 bases. This was 471-bp long and encoded a peptide of 157 amino-acid residues with a calculated mol. wt of 17424 . The nucleotide and predicted amino-acid sequences are shown in fig. 2. The proposed type VI structural gene was found to be bounded by an initiation codon (ATG) at position 336 and a termination codon (TAA) at position 807. At position 646 there was a HindIII restriction site. Other restriction sites are shown in fig. 1 .

\section{Analysis of the $5^{\prime}$ and $3^{\prime}$ nucleotide sequence}

Analysis of the DNA sequence upstream of the ORF showed a set of possible -35 and -10 promoter sequences. The most highly conserved base pairs of the -35 consensus sequence in $E$. coli promoters are -TTGACA- ${ }^{14}$ The hexamer -TAGACA- found at position 260 of this sequence was identical in five of the six base pairs and could, therefore, have fulfilled this function. Harley and Reynolds, ${ }^{15}$ in an analysis 


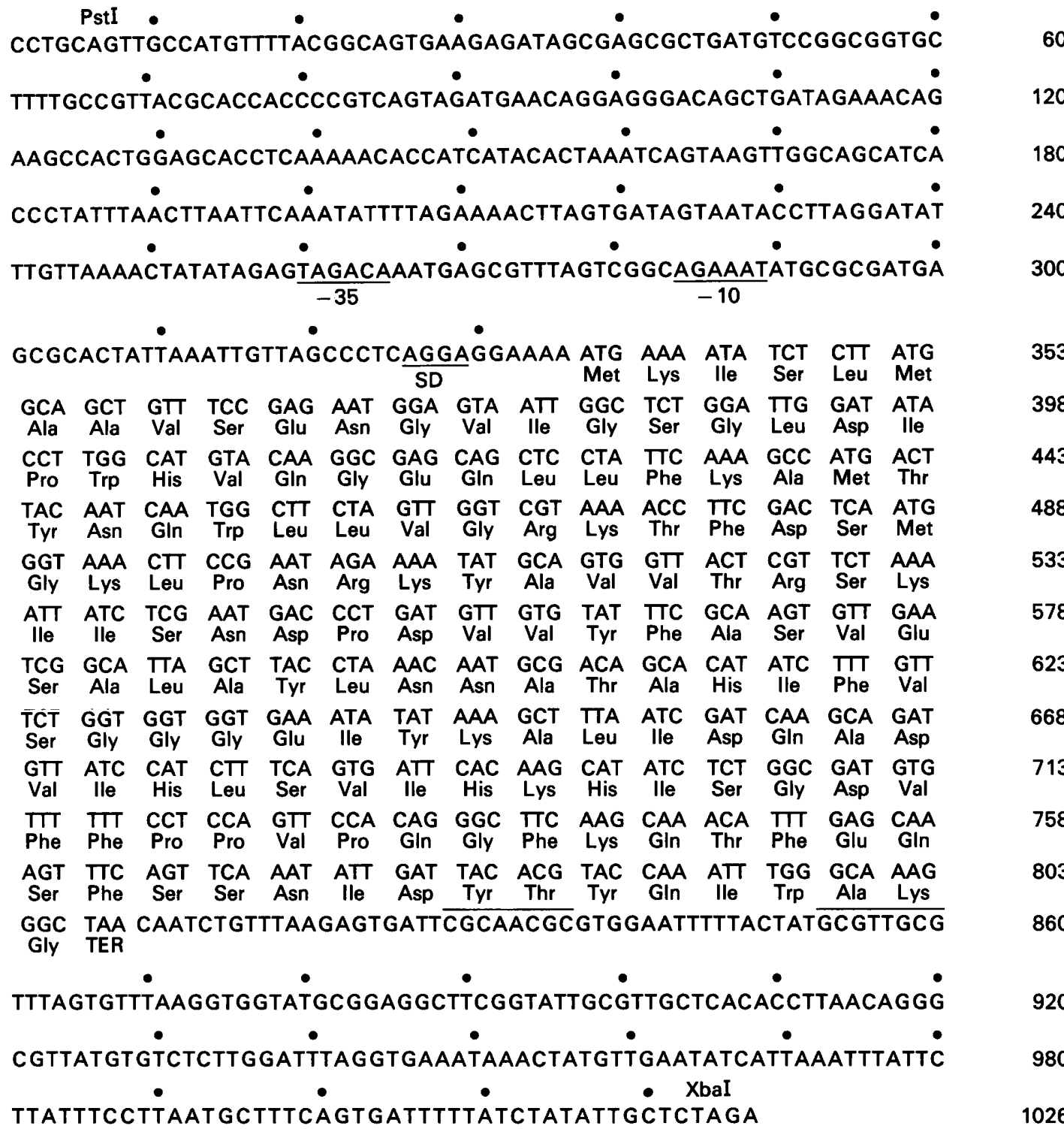

Fig. 2. Nucleotide sequence of the 1026-bp insert. The DHFR coding region extends from base 336 to base 806 . The deduced amino-acid sequence is written below the DNA sequence. The -35 and -10 regions and the ribosomal binding site are underlined. The inverted repeat sequence is overlined.

of 253 E. coli promoters, found that the optimum distance between the -35 and -10 regions was $17 \pm 1 \mathrm{bp}$. Taking this into consideration, the hexamer -AGAAAT-, which was 18-bp downstream from the proposed -35 sequence, could have formed the -10 region. However, this sequence differed in three of the six base pairs found most commonly in $E$. coli -10 sequences, -TATAAT-. If these regions did function as the RNA polymerase binding site, they were further upstream than expected. However, longer leader sequences have been noted previously although their function is not known. ${ }^{4,16}$ There was a ribosomal binding site (-AGGA-) at an appropriate distance from the proposed initiation codon. ${ }^{17}$

A possible transcription termination site was present downstream of the coding region. An inverted repeat sequence centred at position $845 / 6$ could be involved in the formation of a stem and loop structure in which the stem contains 8 bp and the loop 16 bases.
Other features consistent with rho-independent termination were not present.

\section{Comparison of amino-acid sequences}

The types I, V and VI DHFR genes encode polypeptides of 157 amino acids, whereas the gene for the $E$. coli chromosomal DHFR encodes a polypeptide of 159 residues. ${ }^{18}$ These sequences are aligned in fig. 3 and numbered according to the $E$. coli DHFR. Overall amino-acid homology between the type I and type VI enzymes was $63 \%$, but within the first 50 amino acids, where co-enzyme, substrate and inhibitor binding take place, ${ }^{19}$ there was $80 \%$ homology. There was even greater identity $(86.6 \%)$ in the residues $51-65$. Similarly, comparison of the type $\mathrm{V}$ and type VI sequences showed $61 \%$ homology; $78 \%$ of the first 50 residues and $86.6 \%$ of residues $51-65$ were identical. The degree of homology between the chromosomal 


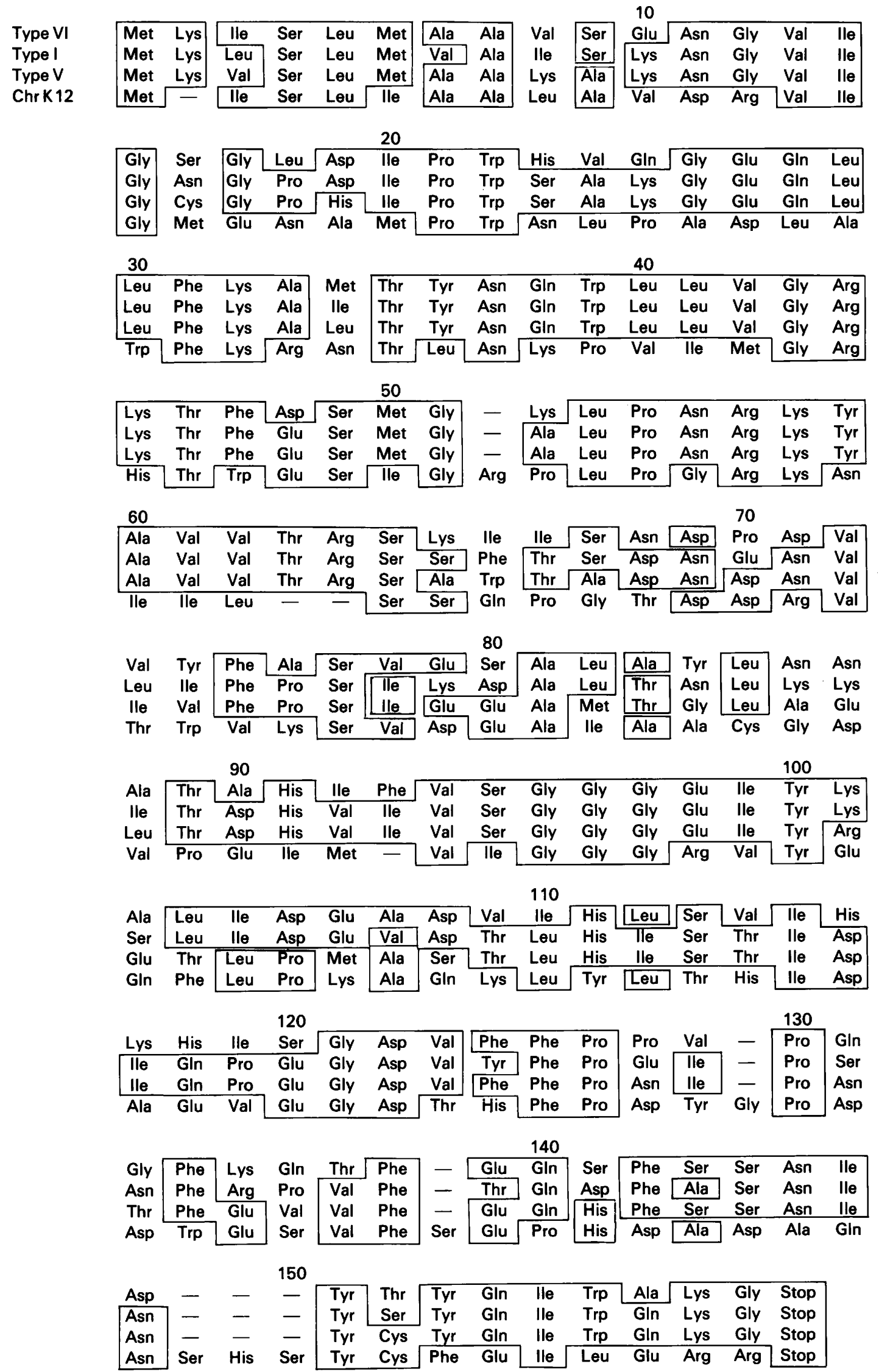

Fig. 3. Alignment of the amino-acid sequences of the type I, V, VI and E. coli $\mathrm{K} 12$ dihydrofolate reductases. The numbering is according to the $E$. coli DHFR. Conserved residues are enclosed. 
DHFR of $E$. coli $\mathrm{K} 12$ and the type VI DHFR was only $31 \%$.

The residues known to be involved in folate binding are $5,6,7,15,20,22,28,30,31$ and $94 .{ }^{20}$ The resistant DHFRs have residues identical to those of $E$. coli $\mathrm{K} 12$ DHFR at positions $5,7,22,31$ and 94 . The remaining five amino acids differ from those of the $E$. Coli K12 enzyme, but the substituted residues (Met-6, Ile-20, Glu-27, Gln-28 and Leu-30) are identical in each of the resistant DHFRs. Similarly, residues associated with methotrexate binding in E. coli are: Ile-5, Ala-7, Asp-27, Leu-28, Phe-31, Ser-49, Ile-50, Leu-54, Arg57, Ile-94 and Thr-113. ${ }^{19,21}$ Only five of these 11 residues were conserved in the resistant DHFRs. These substitutions may explain why the binding affinities of the resistant DHFRs and the chromosomal enzyme differ.

Although the similarity in gene length, DNA and amino-acid homology between type $\mathrm{I}$, type $\mathrm{V}$ and type VI DHFRs suggests common ancestry, the

\section{References}

1. Amyes SGB. The success of plasmid-encoded resistance genes in clinical bacteria. J Med Microbiol $1989 ; 28: 73-83$.

2. Amyes SGB, Towner KJ. Trimethoprim resistance; epidemiology and molecular aspects. J Med Microbiol 1990; 31 : 119.

3. Fling ME, Richards $C$. The nucleotide sequence of the trimethoprim-resistant dihydrofolate reductase gene harbored by Tn7. Nucleic Acids Res 1983; 11 : 5147-5158.

4. Swift G, McCarthy BJ, Heffron F. DNA sequence of plasmidencoded dihydrofolate reductase. Mol Gen Genet 1981; 181 : $441-447$.

5. Sundström L, Rådström P, Swedburg G, Sköld O. Site-specific recombination promotes linkage between trimethoprimand sulfonamide resistance genes. Sequence characterization of $d h f r V$ and sull and a recombination active locus of Tn21. Mol Gen Genet 1988; 213: 191-201.

6. Brisson N, Hohn T. Nucleotide sequence of the dihydrofolatereductase gene borne by the plasmid R67 and conferring methotrexate resistance. Gene 1984; 28: 271-275.

7. Flensburg J, Steen R. Nucleotide sequence analysis of the trimethoprim resistant dihydrofolate reductase encoded by R plasmid R751. Nucleic Acids Res 1986; 14: 5933.

8. Thomson CJ, Amyes SGB. Biochemical properties of the type V plasmid-encoded trimethoprim-resistant dihydrofolate reductase. J Pharm Pharmacol 1988; 40 Suppl: 21 P.

9. Wylie BA, Amyes SGB, Young H-K, Koornhof HJ. Identification of a novel plasmid-encoded dihydrofolate reductase mediating high-level resistance to trimethoprim. J Antimicrob Chemother $1988 ; 22: 429-435$.

10. Wylie BA, Koornhof HJ. Trimethoprim resistance in gramnegative bacteria isolated in South Africa. $J$ Antimicrob Chemother 1989; 24: 973-982.

11. Yanisch-Perron C, Vierira J, Messing J. Improved M13 phage cloning vectors and host strains: nucleotide sequences of the M13 mp18 and pUC19 vectors. Gene 1985; 33: 103119. biochemical properties of these enzymes were distinct. The type V and type VI DHFRs do, however, have certain physical characteristics in common. By Sephadex column chromatography, the mol. wt of the type V DHFR was estimated to be $5000,{ }^{8}$ whereas the gene sequence data showed the mol. wt of the polypeptide to be $17531 . .^{5}$ Similarly, the mol. wt of the type VI DHFR was estimated to be $10000^{9}$ whereas the gene determined a polypeptide of over 17000 . The reason for this behaviour is unknown, but it could be due to the hydrophobicity of the enzyme molecules. ${ }^{22}$ The mol. wt of the type V DHFR was subsequently reported to be 35000 by native polyacrylamide gel electrophoresis (PAGE) ${ }^{23}$ indicating that, like the type I DHFRs, the type V enzyme functions as a dimer. The mol. wt of the type VI DHFR, as assessed by SDS-PAGE, was 17 500. It has not yet been determined whether it functions as a dimer, but the similarities between these three enzymes support this possibility.

12. Maniatis T, Frisch EF, Sambrook J. Analysis of recombinant DNA clones. In: Molecular cloning: a laboratory manual. Cold Spring Harbour, NY, Cold Spring Harbor Laboratory. 1982: 370 .

13. Sanger F, Nicklen S, Coulson AR. DNA sequencing with chain-terminating inhibitors. Proc Natl Acad Sci USA 1977; 74: 5463-5467.

14. Rosenburg M, Court D. Regulatory sequences involved in the promotion and termination of RNA transcription. Annu Rev Genet 1979; 13: 319-353.

15. Harley CB, Reynolds RP. Analysis of $E$. coli promotor sequences. Nucleic Acids Res 1987; 15: 2343-2361.

16. Andrews J, Clore GM, Davies RW et al. Nucleotide sequence of the dihydrofolate reductase gene of methotrexateresistant Lactobacillus casei. Gene 1985 ; 35: 217-222.

17. Shine J, Dalgarno L. Determinant of cistron specificity in bacterial ribosomes. Nature $1975 ; 254$ : 34-38.

18. Smith DR, Calvo JM. Nucleotide sequence of the $E$. coli gene coding for dihydrofolate reductase. Nucleic Acids Res 1980; 8: 2255-2274.

19. Matthews DA, Alden RA, Bolin JT et al. Dihydrofolate reductase from Lactobacillus casei. J Biol Chem 1978; 253: 6946-6954.

20. Bystroff C, Oatley SJ, Kraut J. Crystal structures of Escherichia coli dihydrofolate reductase: The $\mathrm{NADP}^{+}$holoenzyme and the folate. NADP ${ }^{+}$ternary complex. Substrate binding and a model for the transition state. Biochemistry 1990; 29: 3263-3277.

21. Matthews DA, Alden RA, Bolin JT et al. Dihydrofolate reductase: $\mathrm{X}$-ray structure of the binary complex with methotrexate. Science $1977 ; 197$ : 452-455.

22. Towner KJ, Young HK, Thomson CJ, Amyes SGB. Detection in the UK of trimethoprim resistant Escherichia coli encoding the type V dihydrofolate reductase. Eur J Clin Microbiol Infect Dis 1990; 9: 149-150.

23. Thomson CJ. Biochemical analysis of the recent plasmidencoded trimethoprim-resistant dihydrofolate reductases in gram-negative bacteria. PhD thesis, University of Edinburgh, 1990. 